\title{
ILCEA
}

Revue de l'Institut des langues et cultures

d'Europe, Amérique, Afrique, Asie et Australie

39 | 2020

Les humanités numériques dans une perspective internationale : opportunités, défis, outils et méthodes

\section{A Digital Revival of Oriental Studies}

Le retour numérique des études orientales

Dr. L. W. Cornelis van Lit, Dr. James H. Morris and Ms. Deniz Cevik

\section{CpenEdition}

1 Journals

Electronic version

URL: http://journals.openedition.org/ilcea/10327

DOI: $10.4000 /$ ilcea.10327

ISSN: 2101-0609

\section{Publisher}

UGA Éditions/Université Grenoble Alpes

Printed version

ISBN: 978-2-37747-174-4

ISSN: $1639-6073$

\section{Electronic reference}

Dr. L. W. Cornelis van Lit, Dr. James H. Morris and Ms. Deniz Cevik, «A Digital Revival of Oriental Studies », ILCEA [Online], 39 | 2020, Online since 25 February 2020, connection on 09 October 2020. URL : http://journals.openedition.org/ilcea/10327 ; DOI : https://doi.org/10.4000/ilcea.10327

This text was automatically generated on 9 October 2020 .

(C) ILCEA 


\title{
A Digital Revival of Oriental Studies
}

\author{
Le retour numérique des études orientales
}

Dr. L. W. Cornelis van Lit, Dr. James H. Morris and Ms. Deniz Cevik

\section{Introduction}

1 "The Digital Orientalist" is the name of an online magazine focused on using computer technology in research related to one of the domains of the Humanities that can be or has traditionally been called "Oriental." Thus, we mean "Oriental" in the sense of how learned societies use it such as the American Oriental Society, or the Deutsche Morgenländische Gesellschaft, or in the sense of institutions such as Institut national des langues et civilisations orientales in Paris or the School of Oriental and African Studies in London. While the background history of the magazine will explain how the name has a rather innocent origin, we realize that the name is problematic. More than once, people have complained about it, considering it outdated at best, arrogant at worst. We do not mean it to be like that but rather, we see similar problems and solutions related to computer technology, among these various fields of Humanities that come together under the banner of "oriental". In this article, we explain more fully our raison d'être.

\section{The background}

2 Our magazine grew out of a blog with the same name, which the current editor-inchief, Cornelis van Lit, ran between 2013 and 2018. His main motivation to start the blog was to get discussions going on how to practice our jobs and studies in this digital age. From the early 2010s, he was developing little hacks and best practices that made life a bit easier for his own research needs in Islamic Studies. He thought he might as well share them with others, as a means to start such discussions. Since computerproficiency is generally very low in Islamic Studies globally, he did not consider his blog to be "Digital Humanities" but simply focused on the everyday technological problems of a normal workflow. Topics included how to organize files on your 
computer in a useful way, how to strategize for making backups, how to type in Arabic, and critical impressions of different machines to digitize books. Initially, the idea was to write small blog entries in preparation for a general guide on how to use computers in your studies or research, applicable to the Humanities in general and with a low level of entry. Such a book is still a desideratum, since the undergraduate curricula of most programs in the Humanities still pretend like we live in a paper world, but the blog did not develop in this direction.

Instead, Van Lit invested first in reflecting on the future of scholarship, ${ }^{1}$ and then turned his attention to digitized manuscripts. ${ }^{2}$ In 2016, he organized a panel at the Annual Meeting of the American Oriental Society, which was one of the few that brought together people from the different tracks that the conference is usually organized by ("Digital Orientalism: Using computer technology in our day-to-day workflow"). Its success proved that there was a demand for a cross-disciplinary discussion on integrating technology into our research. In 2018, this challenge was taken up as the blog became a magazine. Now, not one person but a team assembled from various disciplines run it. Currently, The Digital Orientalist covers African Studies, Islamic Studies, Ancient Near East Studies, and Japan Studies. Next to each topic being run by an editor, an editor-in-chief and a social media manager round out the team. The expansion of the team and wider breath of topics resulted in an increase of visibility and traffic, with currently about a thousand visitors per month. Although these above-mentioned areas constitute the main categories under which the editors write, the Digital Orientalist is also open to guest contributors and their texts about digital humanities.

4 In terms of content, articles are relatively short (between 500 and 1000 words) and written in accessible, conversational English. This reflects our readership, which includes not only academics, but students and librarians, many of whom desire concise content which can be read during their busy schedules. This also encourages serialization, and readers will therefore notice that longer pieces are often split into a number of parts. Articles can broadly be described as theoretical reflections and practical examples of how computers can be used in a scholar's everyday workflow to improve or reinvent the way in which they work. As such, articles tend to focus on problems and solutions faced by scholars of Asia, Africa and the Middle East in their research. This could include the writers' own development of digital tools and solutions to problems faced in their research, their use and experiences with pre-existent tools, hardware and software reviews, tutorials and interviews. Nevertheless, the Digital Orientalist is not concerned with merely pointing readers to potentially useful resources; it seeks to add value by grounding its articles in the authors' personal experience. The Digital Orientalist could therefore be described as an experiential publication, it is grounded in the experience and reflections of its authors. Rather than talking about using cutting-edge technology to yield extraordinary new scholarly insights, the Digital Orientalists shows readers ways in which we can improve our scholarship here and now.

5 There is a variety of topics that the contributors of the digital magazine write including the use of digital humanities in teaching, the role of digital tools in archaeology, the personalized browser extensions for academic purposes, digital tools for research workflow, digital libraries, digitization and archiving, coding, online resources and use of geo information systems in humanities research. One of the fundamental principles 
behind the existence of the Digital Orientalist is to create a Digital Humanities knowledge base that the researchers could stay up-to-date on the recent "digital" developments in their fields. In doing so, neither the editors nor the contributors of the magazine employs a from above approach. Articles published in the Digital Orientalist are not preoccupied with showing the readers the best ways to integrate computers in their research but with providing a platform for the academics, researchers, librarians, archivists and students to share their experiences with the digital tools, the challenges they face and the solutions they find in using such tools. In other words, the Digital Orientalist seeks to promote interaction between people actively using the digital tools for academic purposes with those who are eager to hear and learn more about these experiences. In this sense, the Digital Orientalist connects people with different backgrounds who have a common interest: the interest in using digital tools in research.

6 As noted, contributors often write about their own projects, the limitations and difficulties associated with these projects, or their experiences engaging with the resources developed by other scholars. For instance, Charles Riley of the Yale University Library who acts as the Digital Orientalist's African Studies editor has contributed an extensive series of posts exploring issues pertaining to different African languages including its scripts and fonts, (Riley, 2018a and 2018b) relevant resources for their study, (Riley, 2019a and 2019b) encoding and its issues, (Riley, 2019c, 2019d and 2019e) and cataloging (Riley, 2019f) amongst other topics. These posts, whilst diverse in terms of linguistic focus, have helped to elucidate issues experienced by African studies scholars and disseminate information pertaining to the intercourse between African Studies and the Digital Humanities to a wider audience. Several of the Digital Orientalist's contributors and editors have also contributed to an ongoing series on digital mapping. This series began with Deniz Çevik's (McGill University) two-part post on using the software Leaflet in order to create digital maps from historical data ( Çevik, 2019a and 2019b). This was followed by Japan Studies Editor, James Morris's (University of Tsukuba), review of mobile applications for accessing historical Japanese maps, (Morris, 2019a) and Islamic Studies Editor, Alex Mallett's (University of Waseda) tutorial for using Google Maps as a visualization tool for historical data pertaining to the origins of Muslim slaves in 16th and 17th Century Malta (Mallett, 2019). A more recent contribution in this series was by Indian Studies Editor, Giulia Buriola (University of Rome), who explored using qGIS to overlay modern and historical Indian maps (Buriola, 2019). These diverse posts on mapping provide readers with concrete examples of the potential uses of mapping software in different academic fields and spatial contexts, whilst simultaneously guiding readers through how to use different pieces of mapping software and the potential limitations with these pieces of software. Other contributions have also offered experiential tutorials for readers, such as the recent guest post by Christine Roughan (New York University) who provided a tutorial on how to train OCR models for Arabic and Syriac with Kraken, (Roughan, 2019), Morris's tutorials on making digital timelines with TimelineJS and interactive stories with Twine for use in the classroom, (Morris, 2019b and 2019c) Islamic Studies contributor, Maxim Abdul Latif's tutorial on how to use Google Translate with a single click, (Abdul Latif, 2019) and Digital Orientalist's owner, Cornelis van Lit's tutorials for using Python to analyze Latin poetry (van Lit, 2017 and 2018a). The Digital Orientalist has also included occasional pieces on longer term, institutional projects such as Utrecht University's “ Bridging the Gap: Digital Humanities and the Arabic-Islamic corpus," (Abdul Latif, 2018) 
the YouTube Channel, Digital Hammurabi, (Lewis, 2019) and van Lit's monograph project Among Digitized Manuscripts. (van Lit, 2018b and 2019) In summation, the publication showcases a breadth of often interrelated content pertaining to the often overlooked intercourse between the Digital Humanities and fields of non-Western study. Much of this material is experiential and focuses on contributors' personal projects or their interactions with resources developed by other scholars or organizations.

This hands-on, low-key approach was quite unique in 2013 and still is. Most platforms dedicated to Digital Humanities are aimed at a more advanced level of using technology, ${ }^{3}$ are merely aggregates ${ }^{4}$ or offer highly tailored tutorials. ${ }^{5}$ We opted to add to the discourse with something different, taking our inspiration from websites outside of academia, specifically the digital time management and personal development scene for creatives and entrepreneurs. This discourse generally offer small, easy to implement workflow improvements, which can be used one by one or at the same time. Such pieces of advice are often called "life hacks", hence the name of one of the most publicly visible websites dedicated to this: Life Hacker. Since we speak from our own expertise as much as possible, and our audience is therefore primarily scholars, students, and librarians, we nevertheless sought to integrate ourselves as much as possible among scholarly online resources. The choice for a name was a primary way to convey this.

Choosing a name was not a rash decision. In brainstorming sessions terms such as "Toolkit" and "Islamic Studies" were favourites, reflecting the practical bend and Van Lit's personal field. "Digital Orientalist" was ultimately favoured for a variety of reasons. One was that it found equivalents in the names The Digital Classicist and The Digital Medievalist. ${ }^{6}$ These initiatives are quite different from The Digital Orientalist in that they are less about knowledge production and more about bringing people into contact, in other words, being a learned society in their own right. Nevertheless, given the proximity of those two fields (Classics and Medieval Studies) to the fields regarded as Oriental, it was considered a good idea to look to them for best practices, among them the naming convention. Considering Van Lit's area of expertise, "Digital Islamicist" would seem to be a natural candidate. However, the term "Islamicist" was deemed to be too close to "Islamist", a term generally used to denote a fundamentalist or otherwise radicalized Muslim. With the proliferation of "online jihad", any confusion needed to be avoided. Beyond that, the problems a typical student or scholar faces in Islamic Studies, are also present in other fields. Even though the articles of the first years only use Islamic Studies as a case study, choosing a name more general than Islamic Studies encouraged the reader to think of applications of the solutions offered to similar problems in other fields. Similarly, through choosing a name more general than Islamic Studies, The Digital Orientalist has ensured that it is not restricted to a single field, and as mentioned now publishes on several fields and geographic regions. This brings us to a final reason to choose The Digital Orientalist, namely, its pithy encapsulation of the mission of the website: to bring into harmony two aspects of our work that seem diametrically opposed. Our work rests on sources and methodologies that far precede the digital age and do not assume it. Yet, our daily reality is to sit behind a computer and use and produce digital resources. How are the two to be married? The term "digital orientalist" consists of a noun and an adjective; the noun is "orientalist", which inherently claims that we are scholars of our fields first, and only 
in that capacity are we changed or characterized by the adjective "digital", indicating that we can (and should) adopt digital traits to enhance our work and workflow.

\section{Reclaiming the terms "Orientalist" and "Orientalism"}

In the nineteenth and twentieth centuries, the term "Orientalist" was generally used to describe a European or American scholar who drew in their Humanities research on the Orient (Macfie, 2002: 3), by which everything beyond the Bosporus could be included. The term lived a very precise breaking point with the publication of Edward Said's (1935-2003) 1978 book Orientalism (MacKenzie, 1995: 2), soon followed by other, related criticisms (Macfie, 2002: 5-7). It is worth quoting John MacKenzie in full here to understand the impact Said had;

[Said's work] transformed "Orientalism", in which the Orient is appropriated by the Occident by being turned into a structure of myth prefabricated for western use, into one of the most ideologically charged words in modern scholarship (MacKenzie, 1995: 4).

For Said, the mistaken epistemological and existential dichotomy between Orient and Occident and the inappropriate power dynamic of the Occident speaking on behalf of the Orient, were entangled and interdependent with research of teaching on the Orient (Said, 2003: 2-4), and so the latter had to go too if the others were to be challenged effectively.

11 A fair number of institutions and learned societies went so far as changing their name, to reflect a turn to "Area Studies" (Halbfass, 1997). This, however, meant that cohesion or mutual influence between different "areas" became underemphasized, while the modern era became overemphasized as areas became easier to define with the rise of nation states. Furthermore, whereas "Orientalism" had become associated with European colonial projects, "Area Studies" became associated with American Cold War foreign policy (Winichakul, 2016: 1). This has led to the development of a discipline and an associated culture which Vicente L. Rafael notes has;

been integrated into larger institutional networks, ranging from universities to foundations, that have made possible the reproduction of a North American style of knowing, one that is ordered toward the proliferation and containment of Orientalisms and their critiques (Rafael, 1994: 91).

Moreover, as Claudia Derichs notes, the process of defining areas of study according to an "Area Studies" framework is based on political decisions and do not necessarily reflect empirical realities (Derichs, 2014). It is, then, only natural for us scholars who are faced with similar issues to not meet on the terms of "Area Studies" but to seek a different vocabulary.

One candidate could be "Cultural Studies". As elucidated by Mario Aguilar, the study of "culture" has historically and contemporarily relied on an assumed cultural uniformity of its subjects' culture (Aguilar, 2004: 299-313). Thus we are faced with problems reminiscent of "Religious Studies" and its struggle of the inherent Protestant bias in the definition of religion (Asad, 1993: 27-54; Platvoet \& Molendijk, 1999). Indeed, it strikes us all too close to Said's original criticism of Orientalism. It is therefore for our purposes of no particular use.

If we reflect back on our initial ambition, to meet each other on common issues in our methods and practices, we can see that one umbrella term would be methodology 
insofar as a computer is involved. Such a discussion could, of course, be called "Digital Humanities," but here in lies an issue. We are not concerned with any discussion on how to use computers in Humanities research.

\section{When the Orient meets the Digital World}

15 For the fields that fall under the umbrella term "Oriental", research is based on historical records often consisting of manuscripts, structures, coins, and art. Computer technology offers the opportunity to bring together sources of mixed nature, because each can be represented by a digital surrogate. Whereas coins and manuscripts, for example, are made of different materials with different methods, in the digital sphere they are both digital files (image and text files) made in identical ways. Thus, whereas coins and manuscripts were hard to integrate in a research project before the advent of the computer because of the radically different approaches needed and because they are often stored in entirely different places and institutionalized differently, now it is relatively easy to have them exist side by side, in both the research and the publication phase.

16 Our fields also have in common that our source materials are usually kept in faraway and disparate places. In the digital world, however, it is possible to bring together sources from all over the world into one workflow. This kind of opportunity can make an enormous impact on our fields-where before we needed to invest large sums of money to take trips to faraway libraries and maybe have enough time to study a few manuscripts in total, we now have the ability to pool together a larger set of manuscripts for less money, and on top of that have the ability to compare the manuscripts side by side in real time.

It may seem that processing ancient manuscripts is common to other fields such as Medieval Studies, but our manuscripts are different in kind. The most notable differences with manuscripts as they are known in Europe are the materials used, the shape and the method of usage of the codex, and the climate in which they were produced and stored. The content itself is distinctly different too. For examples, we may encounter different directions of writing, different number systems, different calendars, and different naming conventions. All these differences make the Westernbuilt world of consumer technology an ill fit to our needs and even DH specific tools often do not offer the support for even the most basic of our needs (for example, right to left writing direction). Thus, while it is true that among our fields there is still considerable difference, what unites us is the need to adapt off-the-shelve solutions (usually developed within fields focused on Europe). Since resources are incredibly limited, and the problems we face particularly specific, solutions are not going to come from anyone but ourselves. As the entry level to use technology in an active, productive sense gets lower as time progresses, we propose that herein lies the strength of technology for us: we are now more than ever able to adapt and transform solutions to the needs specific to our field.

What separates us too is that our source material is preserved in a different way. Much of our resources are only available in faraway countries within libraries with often very little means to support researchers. Ironically, with human labour being the biggest cost for digitization, it is exactly the institutions we rely on that have the easiest time digitizing their collections. For many of our oriental fields, the corpus of available 
digitized manuscripts is many times larger than what is available in comparable fields focused on Europe. It should be noted that this can come at the cost of quality, but for most purposes the digital surrogates are sufficient.

Lastly, what unites us and sets us apart from other fields is the limited quantity and low quality of metadata available, in other words, the catalogues. This is nothing to be proud of, for us, since most fields in Oriental studies sorely lack advanced catalogues, let alone a good grasp of what is available out there. Researchers in fields concerned with Europe have a much more advantageous starting position, since they can use the catalogue details and other meta data that are already there (and probably available in a digital, user friendly way) to jump straight into the interesting bits. ${ }^{7} \mathrm{We}$, on the other hand, may have to move across all stages of work on the object: from digging up, to identifying, to cataloguing, to digitizing, and only then to singling out the most interesting bits for inclusion in our research. The computer technology available today makes all of this more or less possible, even for a lone researcher. Large-scale digitization of documents and manuscripts made the historical records accessible more than ever. A digitized manuscript can be accessed through the online catalogues and can be read with the help of computerized manuscript, palaeography and textual analysis tools. Either online or part of the curricula, text mining and analytics courses became more and more popular among humanities scholars. Although textual records are still of great importance for the archives, graphic and cartographic material took on a new significance in the Digital Era as the data they contain can be processed and manipulated by different tools. A digitized version of a historical map that was long forgotten in the archives can now be used by a humanities researcher as a base map in a cartography project. ${ }^{8}$ While other scholars in the Humanities may be satisfied with being passive users of technology, scholars in Oriental disciplines can, with only little training, become active producers of technology to solve issues that are part and parcel of their work.

Oriental studies is quite different from other fields in one other aspect, namely, the necessity to incorporate sources from a variety of languages with different scripts. Sometimes this is needed because the same phenomenon is reported in different languages, and sometimes it is needed to trace the trajectory of a text across centuries and continents. Native support for the languages and scripts we are interested in is getting better, especially since the advent of Unicode. However, there are still cases where not all details of a script can be captured or where a script is simply missing. As such, we are often faced with relying fully or mixing in Latin script, unable to let our sources speak in their own words. Thus, on one hand we are happy to be able to encode these different texts and connect them to create a flexible digital environment in which different texts can be turned on and off at will. On the other hand, we often have to be creative to capture the details that matter to us, and we have to endure that technology is fundamentally developed by and for a Western audience. For example, why is it that programming languages and encoding standards (such as TEI) are English? ${ }^{9}$ And why is it that much of the most valuable parts of the internet are stored on servers in the US or the European Union, political entities which then go on to claim to have jurisdiction over them? Is this an obscene barrier to entry, a flagrant example of how Orientalism in the bad sense of the word is still holding sway? We are not in a place to pursue this point, but we do think that we ought to look for solutions to the limitations that are imposed on us, and doing so in an interdisciplinary setting is very fruitful. 


\section{Digital Orientalism at the Universities}

21 in an awareness of shared digital aspects of ours, but also a shared desire for formal education and training in digital tools designed specifically for Oriental studies programs. A standardized training in digital tools with a focus in Oriental Studies research could also increase demand for new digital tools specific to Orientalists, which may in turn encourage the consumer software industry to offer more inclusive products. This brings us to the importance of integrating digital approaches into the Oriental Studies undergraduate and graduate level programs.

Such an approach requires a full-fledged definition of what we mean by "digital aspects" of research in Oriental Studies compared to the "non-digital aspects". First, we argue that the "digital aspects" do not signal the demise of the analogue or conventional methods but they rather build upon them. Having a digital aspect is a preference over the non-digital aspects, not the abandonment of the entire traditionally established theories and methods. We agree with Birnbaum, Bonde and Kestemont when they say:

the "original" objects of our research are most often mediated by the printed or online text or the slide or digital image. The difference between the digital humanities and their less digital counterpart has become more a matter of degree than of kind (2017: 3).

Second, the use of data in humanities and social sciences existed long before the Digital Humanities (DH) emerged as a discipline. John Snow's famous discovery of the relationship between cholera cases and water pumps in London was based on an early attempt of data visualization in mid-19th century (Paneth, Rachman \& Rip, 2003: 397). His study was very straightforward: he identified and mapped the location of each death and that of the water pump. A simple data visualization and mapping task convincingly uncovered the mystery around cholera.

In today's digital world following the advances in computer science, cutting-edge web technologies and digital tools, one would think that it is much easier to do what John Snow has done with paper and pencil. There is indeed an extensive variety of tools that students and scholars can use for their research in humanities and social sciences no matter what areas they are interested in. However, as the number of these tools grows, four important elements also change accordingly: the complexity of the tools increases, the access becomes a more complicated issue, the documentation becomes longer and not all areas and disciplines benefit equally from existing tools. The better the tools become, the more guidance the users need. As Elias Muhanna argues, "This transformation in the technique and approach of scholarship prompts us to consider the lines of inquiry opened by these new resources, just as it asks the question of what methodological instincts and practices may be eroded by the rise of computational paradigms" (2016: 3).

Dennis Tenen's (2016: 83) interpretation of the digital humanities as the "computational turn" of humanities is quite helpful to understand why the time has come for the departments to consider updating their undergraduate and graduate curricula. According to Tenen, DH is part of this wider phenomenon of computationalization that all major disciplines have experienced, and it merely is the 
historian's, the literary scholar's and the philosopher's turn (Ibid.: 83). The argument here is twofold: first, humanities disciplines are not the first and only ones that encounter the dilemma of adopting or neglecting the technology and second, digital tools can supplement "the traditional research toolkit" of the humanities, just as it did for other fields such as social sciences, linguistics, natural sciences (Ibid.: 83). At this point, a question arises-a question that is of interest to all humanities departments but especially the programs that correspond to our definition of Oriental studies. Why do most undergraduate programs in history, in literature and in area studies not include courses on digital humanities' tools whereas their counterparts in geography, in sociology, in psychology include practical courses such as on GIS, data science, and quantitative methods? Why do we think that a text mining or a digital curation course for Oriental studies programs are not as crucial as a GIS course for a geography program? The reason lays not only in our perception of humanities as theory-oriented disciplines that lack technical components but also in departments' understanding of what an Oriental Studies scholar should look like. The stereotypical perception of an Oriental Studies Scholar working with dusty manuscripts written in exotic scripts is perhaps more alive than we like to admit. Forbidding the term "Oriental" does not solve this perception, indeed, it merely hides it. This is why we wish to bring the term to the surface again, to pierce through the false romanticism that our work could only be done when we are in a dusty archive, and to advance the idea that we can and should be computer literate just as the scholars of other fields. Additionally, as long as computer technology is not sufficiently integrated into our curricula, it remains important to bundle our strengths and exchange best practices.

Even so, we argue that the fields of Oriental Studies require more attention from both the scholarly and technical communities. As we outlined above, there are different factors that differentiate Oriental Studies from other fields in terms of interaction with digital tools. Due to these factors, both students and scholars can find themselves in a paradoxical position where they must act as both creators and users of the digital tools, as it is often the case that specific adaptions need to be made to off-the-shelve software. For the long-term future, it would be excellent to see undergraduate and graduate programs include training to create or adapt computer technology, for the short-term future, all we can ask for is to do it ourselves. By combining our strengths and starting a conversation across our fields, we stand a much better chance of making progress already now.

The second reason why our field requires more attention is the disproportionality of resources of Digital Humanities across the globe. It is no secret that an overwhelming majority of the Digital Humanities centers are in Europe and North America (Risam, 2017: 379). Risam's findings align with the criticisms of Eurocentrism in Digital Humanities as outlined by Sharpe and Powell (2018: 167). This means that our partners (libraries, museums, archives, etc.) often lack the expertise, equipment and logistics that are taken for granted in Europe. It further means that university programs in the regions whose history we study suffer an even greater lack of formal education opportunities as our colleagues do in European institutions. This, again, puts a higher emphasis on being self-reliant and requires not only passive, consumer knowledge but active, producer knowledge of computer technology. 


\section{Conclusion}

Through similar motivations and similar dissatisfactions, we have sought conversation partners on discussing best practices of using computer technology in our research. As those partners are very few in each of our respective fields, we have found it tremendously beneficial to look over the boundaries of our disciplines and meet each other. This is what The Digital Orientalist is first and foremost: a place to exchange best practices that are rooted in examples of a specific field but can be applied elsewhere. Since technological and institutional challenges are similar for the fields formerly known as "Oriental", we have found it beneficial to revive this term. Despite all its bad implications, it serves for us as the greatest common divisor while also reminding ourselves of the formidable task at hand: to bring cutting-edge technology into the tested and tried practices and methods of our fields.

\section{BIBLIOGRAPHY}

ABdul LATIF Maxim (2019), “Google Translate with One Click (Mac)”, online on Digital Orientalist: <https://digitalorientalist.com/2019/02/28/google-translate-one-click-mac/> (December 17, 2019).

ABDUl LATIF Maxim (2018), “DH Project at Utrecht University: Bridging the Gap”, online on Digital Orientalist: <https://digitalorientalist.com/2018/09/27/bridging-the-gap/> (December 17, 2019).

Aguilar Mario (2004), “Changing Models and the 'Death' of Culture: A Diachronic and Positive Critique of Socio-scientific Assumptions.", L. Lewis J. \& M. Aguilar (eds), Anthropology and Biblical Studies: Avenues of Approach, Leiderdorp: Deo Publishing, 299-313.

ASAD Talal [ed.] (1993), "The Construction of Religion as an Anthropological Category", Genealogies of Religion: Discipline and Reasons of Power in Christianity and Islam, Baltimore: Johns Hopkins University Press.

Birnbaum David J, Bonde Sheila, \& Kestemont Mike (2017), "The Digital Middle Ages: An Introduction", Speculum. A Journal of Medieval Studies, 92(S1), 38, <https://doi.org/10.1086/694236>. BURIOLA Giulia (2019), “Mapping Ancient Indian Urban Spaces”, online on Digital Orientalist: <https://digitalorientalist.com/2019/12/04/mapping-ancient-indian-urban-spaces/> (December 17, 2019).

ÇEVIK Deniz (2019a), “Making Online Interactive Maps with Leaflet (Part 1)”, online on Digital Orientalist: <https://digitalorientalist.com/2019/01/03/making-online-interactive-maps-withleaflet-part-1/> (December 17, 2019).

ÇEVIK Deniz (2019b), “Making Online Interactive Maps with Leaflet (Part 2)”, online on Digital Orientalist: <https://digitalorientalist.com/2019/09/24/making-online-interactive-maps-withleaflet-part-2/> (December 17, 2019). 
DERICHS Claudia (2014), "Reflections: Normativities in Area Studies and Disciplines", TRAFO - Blog for Transregional Research, <https://trafo.hypotheses.org/1372>.

HALBFASS Wilhelm (1997), "Research and Reflection: responses to my respondents”, Poznan Studies in the Philosophy of the Sciences and the Humanities, 59, 587-594.

MACKeNZIE John M. (1995), Orientalism: History, theory and the arts, Manchester: Manchester University Press.

LEWIS Megan (2019), “The Value of Digital Outreach”, online on Digital Orientalist: <https:// digitalorientalist.com/2019/06/21/the-value-of-digital-outreach/> (December 17, 2019).

MACFIE Alexander Lyon (2002), Orientalism, London: Routledge.

MALLETT Alex (2019), “GSM: A Lesson for Beginners, by a Beginner”, online on Digital Orientalist: <https://digitalorientalist.com/2019/10/22/gsm-a-lesson-for-beginners-by-a-beginner/> (December 17, 2019).

MORRIS James Harry (2019a), “Apps for Viewing Historical Japanese Maps”, online on Digital Orientalist: <https://digitalorientalist.com/2019/10/15/apps-for-viewing-historical-japanesemaps/> (December 17, 2019).

MORRIS James Harry (2019b), “Creating a Digital Timeline”, online on Digital Orientalist: <https:// digitalorientalist.com/2019/01/23/creating-a-digital-timeline/> (December 17, 2019).

MORRIS James Harry (2019c), "Historical Storytelling with Twine”, online on Digital Orientalist: <https://digitalorientalist.com/2019/05/27/historical-storytelling-with-twine/> (December 17, 2019).

MuHAnNA Elias [ed.] (2016), The Digital Humanities and Islamic \& Middle East Studies, Berlin: De Gruyter.

PANETH Nigel, RAcHMAN Stephen, \& RIP Michael (2003), Cholera, Chloroform, and the Science of Medicine: A Life of John Snow, Cary: Oxford University Press, Incorporated.

Platvoet Jan G., MolendijK Arie L. [eds] (1999), The Pragmatics of Defining Religion, Leiden: Brill.

RAFAel Vicente L. (1994), “The Cultures of Area Studies in the United States”, Social Text, 40, 91111.

RILEY Charles (2018a), "Notes on the Study of Loma", online on Digital Orientalist: <https:// digitalorientalist.com/2018/10/08/notes-on-the-study-of-loma/> (December 17, 2019).

RILEY Charles (2018b), “Encoding the Bassa Vah script of Liberia”, online on Digital Orientalist: <https://digitalorientalist.com/2018/11/12/encoding-the-bassa-vah-script-of-liberia/> (December 17, 2019).

RILEY Charles (2019a), “Paths to understanding Kpelle”, online on Digital Orientalist: <https:// digitalorientalist.com/2019/02/12/paths-to-understanding-kpelle/> (December 17, 2019).

RILEY Charles (2019b), “Encountering the Vai script”, online on Digital Orientalist: <https:// digitalorientalist.com/2019/09/10/encountering-the-vai-script/> (December 17, 2019).

RILEY Charles (2019c), “A close look a N'ko”, online on Digital Orientalist: <https:// digitalorientalist.com/2019/03/13/a-close-look-at-nko/> (December 17, 2019).

RILEY Charles (2019d), “The Outlook for ADLaM”, online on Digital Orientalist: <https:// digitalorientalist.com/2019/05/17/the-outlook-for-adlam/> (December 17, 2019). 
RILEY Charles (2019e), “Minding Mende”, online on Digital Orientalist: <https://

digitalorientalist.com/2019/04/12/minding-mende/> (December 17, 2019).

RILEY Charles (2019f), “Cataloging Ethiopian Materials”, online on Digital Orientalist: <https://

digitalorientalist.com/2019/12/10/cataloging-ethiopian-materials/> (December 17, 2019).

RISAM Roopika (2017), “Other Worlds, Other Dhs: Notes Towards a Dh Accent”, Digital Scholarship in the Humanities, 32(2), 377-84, <https://doi.org/10.1093/llc/fqv063>.

Roughan Christine (2019), "Using Kraken to Train your own OCR Models”, online on Digital Orientalist: <https://digitalorientalist.com/2019/11/05/using-kraken-to-train-your-own-ocrmodels/> (December 17, 2019).

SHARPE Celeste Tường Vy \& POWELl Timothy B. (2018), "Making Digital Humanities Tools More Culturally Specific and More Culturally Sensitive”, J. Travis \& J DeSpain (eds), Teaching with digital humanities: Tools and methods for nineteenth-century american literature (Topics in the digital humanities), Urbana: University of Illinois Press, 167-184.

SAID Edward W. (2003), Orientalism, London: Penguin Books.

TENEN Denis (2016), “Blunt Instrumentalism: On Tools and Methods”, M. K. Gold \& L. F Klein (eds), Debates in the digital humanities, Minneapolis: University of Minnesota Press, 83-91.

VAN LIT Cornelis (2017), “Tackling Poetry with Python”, online on Digital Orientalist: <https:// digitalorientalist.com/2017/12/11/tackling-poetry-with-python/> (December 17, 2019).

VAN LIT Cornelis (2018a), “Tackling Poetry with Python (2)”, online on Digital Orientalist: <https:// digitalorientalist.com/2018/05/24/tackling-poetry-with-python-2/> (December 17, 2019).

VAN LIT Cornelis (2018b), “Announcing a Handbook for DH and Manuscript Studies”, online on Digital Orientalist: <https://digitalorientalist.com/2018/11/08/announcing-a-handbook-for-dhand-manuscript-studies/> (December 17, 2019).

VAN LIT Cornelis (2019), “Among Digitized Manuscripts: A Book”, online on Digital Orientalist: <https://digitalorientalist.com/2019/11/13/among-digitized-manuscripts-a-book/> (December 17, 2019).

WINICHAKUL Thongchai (2016), “The Changing Landscape of Asian Studies”, Asian Studies, 62(1), 18.

\section{NOTES}

1. Resulting in an article: Lit L. W. C. van (2015), "The Digital Orientalist: Scholarship is becoming bigger and better", MELA Notes, Middle East Librarians Association, 88, 1-8.

2. Resulting in a book: Lit L.W. C. van (2020), Among Digitized Manuscripts: Philology, Codicology, Paleography in a Digital World, Leiden: Brill (Handbuch der Orientalistik series).

3. Such as Digital Humanities Now (<http://digitalhumanitiesnow.org>). In this category also fall weblogs, of which there are plenty run by people in Digital Humanities.

4. Such as the projects page of The European Association for Digital Humanities (<https://eadh.org/ projects $>$ ), or TAPoR (<http://tapor.ca/>).

5. Such as The Programming Historian (<https://programminghistorian.org $>$ ).

6. <http://www.digitalclassicist.org>, <https://digitalmedievalist.wordpress.com>. 
7. This is true for similar resources, such as indexes, concordances, and bibliographies. The Index Thomisticus, often regarded as the beginning of $\mathrm{DH}$, is a prime example of this. See <http:// www.corpusthomisticum.org> and a continuation at <https://itreebank.marginalia.it>.

8. One example of this is: <https://www.sehir.edu.tr/en/research/research-centers/center-forurban-studies>.

9. There are examples that this need not be the case, for programming in Arabic, see <https:// github.com/SimplyAhmazing/noor> and <http://nas.sr/قلب/>.

\section{ABSTRACTS}

The Digital Orientalist is a multidisciplinary and international online magazine that publishes short articles on using information technologies and digital humanities methods in Oriental Studies disciplines. It consists of the articles on a variety of topics written by scholars, students and librarians from different countries. These topics include but not limited to Islamic Studies, Japanese and East Asian Studies, Archaeology, Information Science, Digital Cartography, African Studies and Indian Studies. This article aims to explain the Digital Orientalist's raison d'être as well as the way it uses the term "Orientalist". It highlights the importance of the new technologies and digital humanities in research and teaching of Oriental Studies.

The Digital Orientalist est une revue numérique à la fois multidisciplinaire et internationale qui publie des courts articles sur l'utilisation des méthodes numériques et des technologies d'information dans les études orientales. Elle contient des articles sur les divers sujets écrits par les chercheurs, étudiants et bibliothécaires de différents pays. Les études islamiques, les études japonaises et asiatiques, l'archéologie, l'informatique, la cartographie numérique, les études africaines et les études indiennes sont parmi ces sujets. Cet article vise à expliquer la raison d'être de la revue ainsi que la façon dont la revue utilise le terme «orientaliste ». Il fait valoir l'importance de l'utilisation des nouvelles technologies d'information dans la recherche et l'enseignement des études orientales.

\section{INDEX}

Mots-clés: Numérique, humanités, orientaliste, revue, méthodes

Keywords: Digital, humanities, orientalist, journal, methods

\section{AUTHORS}

\section{DR. L. W. CORNELIS VAN LIT}

Postdoctoral Researcher, Utrecht University (The Netherlands)

\section{DR. JAMES H. MORRIS}

Assistant Professor, University of Tsukuba (Japan) 


\section{MS. DENIZ CEVIK}

Master of Information Studies Student, McGill University (Canada) 